\title{
El nomen Flavius en Lusitania: su inserción en las estructuras onomásticas y sociales provinciales
}

\author{
Henar Gallego Franco *
}

\begin{abstract}
RESUMEN SUMMARY
El presente trabajo evalúa la huella epigráfica del nomen Flavius en Hispania Lusitania, determinando su contribución al mapa gentilicio de la provincia así como al proceso romanizador y urbanizador de su territorio. Se estudian igualmente las características onomásticas, socioeconómicas e ideológicas de sus portadores.

In the researching work we analyze the epigraphical trace of the roman name Flavius in Hispania Lusitania, showing its contribution to the provincial onomastic background and the romanization and urban process in this land. Also, we study the onomastic, socioeconomic and ideological characteristics of the members of the gens Flavia in this roman-spanish province.
\end{abstract}

Las fuentes epigráficas latinas del Imperio Romano Occidental reflejan una gran expansión en la onomástica personal de los llamados nomina imperiales, debido a que a menudo los nuevos ciudadanos romanos provinciales elegían como gentilicio que expresara su nuevo estatus jurídico el del emperador bajo cuyo reinado accedieron al mismo. En este sentido, la presencia del gentilicio romano Flavius ${ }^{1}$ en las fuentes epigráficas de Hispania habría de vincularse con la sobresaliente

Historia Antigua. Universidad de Valladolid.

W. SCHulze, Zur Geschichte Lateinischer Eigennamen, Berlin, 1966, 167. PIR² F 182-445. 
acción romanizadora y municipalizadora de la dinastía Flavia, que arranca con la concesión del ius Latii por Vespasiano a las provincias hispanas. Sin embargo, y a pesar de la destacada generosidad de esta medida, Flavius no se encuentra en la epigrafía hispanorromana en el grupo de los nomina de aparición más frecuente ${ }^{2}$, contraste que ya ha sido puesto de manifiesto hace tiempo ${ }^{3}$. Hay que tener en consideración, además, que esta práctica onomástica de los nuevos ciudadanos de tomar el nomen del emperador se encuentra más arraigada en las provincias de romanización más tardía, como son las del área danubiana ${ }^{4}$, mientras que en Hispania, en cambio, el arranque temprano del proceso romanizador explica que el protagonismo de los nomina imperiales fuera claramente inferior al de otras regiones del Occidente Romano ${ }^{5}$.

En el presente trabajo nos proponemos abordar, en base a las fuentes epigráficas, un estudio de los portadores del gentilicio Flavius en

2 J. M. Abascal Palazón, Los nombres personales en las inscripciones latinas de Hispania, Murcia, 1994, 30, le muestra fuera del grupo de los diez gentilicios más repetidos, con 183 testimonios en total, de manera que queda fuera de este sector privilegiado, capitaneado por lulius y Valerius (803 y 718 casos respectivamente), sitúandose, además, en función del número global de testimonios, a notable distancia de éstos. Nuestra búsqueda reciente a través de las fuentes epigráficas hispanorromanas nos ha proporcionado poco más de 300 testimonios, de los cuales 67 corresponden a la provincia Lusitania. Sin embargo, es de suponer que los hallazgos de los últimos años hallan hecho aumentar también el número de los testimonios de los nombres gentilicios más populares.

3 G. ALFÖLDY, «Notes sur la relation entre le droit de cité et la nomenclature dans l'Empire romain», Latomus, XXV.1, 1966, 50.

4 G. ALFOLOY, “Notes sur la relation entre le droit de cité et la nomenclature dans l'Empire romain", Latomus, XXV.1, 1966, 46; A. Mócsy, Die Bevölkerung von Pannonien bis zu den Markomannenkriegen, Budapest, 1959, 148. De hecho, los Flavii se manifiestan como un grupo gentilicio de sobresaliente presencia en el mapa onomástico de otras provincias del Occidente romano: así en Germania, cfr. M.R. Garcia MARTinez, Germania Romana. Las estructuras sociales, Valladolid, 1999, 49, 225, es el tercero más numeroso en Germania Superior y el cuarto en Germania Inferior, también en las provincias del Alto y Medio Danubio, donde ocupa la cuarta posición entre los gentilicios más numerosos en Rhaetia y Pannonia, y la séptima en Noricum, cfr. H. GALLEGo Franco, Las estructuras sociales del Imperio romano. Las provincias de Rhaetia, Noricum, Pannonia Superior e Inferior, Valladolid, 1999, 78, 132, 280.

5 Cfr. J. M. ABASCAL PALAzón, Los nombres personales en las inscripciones latinas de Hispania, Murcia, 1994, 28-30: en Hispania el nomen lulius es el único de tipo imperial que se encuentra entre los diez gentilicios más numerosos en estas provincias, y más distanciados se constatan ya los de Flavius y Aelius. G. Al.FÖLDY, "Notes sur la relation entre le droit de cité et la nomenclature dans l'Empire romain", Latomus, XXV.1, 1966, 46-47 y H. GALSTERER, "Diritto latino e municipalizzazione nella Betica". Teoria y práctica del ordenamiento municipal en Hispania. Revisiones de Historia Antigua. II, Vitoria, 1996, 217, sobre la menor frecuencia con que en Hispania los nuevos ciudadanos toman el nomen del emperador. 
Hispania Lusitania, atendiendo a las características de sus esquemas antroponímicos, su posición en el mapa gentilicio provincial, así como a las formas y peculiaridades de su integración en las estructuras sociales de la provincia. Tomaremos también en consideración la incidencia en la epigrafía provincial de otros onomásticos derivados, como pueden ser los cognomina Flavinus/a y Flavianus/a y la posible relación de sus portadores con los Flavii hispanorromanos de Lusitania.

El gentilicio Flavius presenta en Lusitania un total de 67 testimonios ${ }^{6}$ que suponen aproximadamente un $22 \%$ del total de los recogidos en Hispania. Su entidad cuantitativa es por tanto muy similar a la de la Bética $(22 \%)$ y marcadamente inferior a la de la Tarraconense $(56 \%)$, siendo esta última la provincia hispanorromana donde el gentilicio se concentra con mayor fuerza. El aporte menor, por tanto, lo hace la Bética, cuyo porcentaje es similar al de Lusitania pero cuyo volumen global de fuentes epigráficas es muy superior al de ésta última. La gens Flavia se distribuye en territorio lusitano de forma desigual. El conventus Emeritensis aglutina algo más de la mitad de los testimonios (51\%), casi una tercera parte de los mismos se localizan en el conventus Scallabitanus, y sólo un $15 \%$ de ellos se situan en el conventus Pacensis, en el cuadrante sur de la provincia. Ahora bien, la ubicación de los Flavii lusitanos suele estar estrechamente ligada al ámbito urbano, y así les hallamos preferentemente en núcleos urbanos de distinta importancia, así como en su área próxima de influencia.

En el conventus Emeritensis hay que tener presente que la concentración de Flavii en Emerita Augusta, capital del convento y capital provincial, es tan fuerte que desequilibra las conclusiones de un análisis de los datos. Más de los dos tercios de los testimonios del conven. to se ubican en esta colonia, y ella sola aporta una tercera parte del total de testimonios provinciales. Ninguna otra ciudad lusitana presenta una incidencia del gentilicio comparable con la que hallamos en Emerita, y en la que bien pudo haber sido de gran influencia la fuerza de atracción ejercida por la colonia en los desplazamientos intraconventuales e intraprovinciales. Dejando a un lado el foco emeritense, hallamos testimonios puntuales del gentilicio en Norba, Turgalium, Augustobriga,

6 Contabilizamos también como testimonios individuales en nuestro cuadro de datos epi. gráficos las filiaciones y los genitivos de patronos de libertos o dueños de esclavos. 
Caesarobriga, y Ciudad Rodrigo (Mirobriga?), y también en algunas localidades secundarias de ambiente marcadamente indígena, como en un santuario de Ataecina en Alcuéscar (Cáceres) ${ }^{7}$ y en el enclave de Hinojosa de Duero (Salamanca) ${ }^{8}$. En el conventus Scallabitanus los grupos de mayor peso cuantitativo de los Flavii se sitúan en la civitas Igaeditanorum y en Olisipo y su entorno, localizándose además el gentilicio en Conimbriga, en la proximidad de Aeminium y Collipo, en la zona minera de Penamacor ${ }^{9}$, y en Lamego, localidad en el límite norte del convento, junto al río Duero ${ }^{10}$. Finalmente, en el conventus $\mathrm{Pa}$ censis hallamos los testimonios del nomen Flavius en Salacia y su entorno, en Balsa y Mirobriga, y en localidades menores estrechamente vinculadas con el entramado viario, como Elvas (Dipo?), Serpa y Vilaverde de Ficalho (Serpa) ${ }^{11}$.

De todos los núcleos urbanos mencionados, sólo una minoría son coIonias y municipios de promoción pre-flavia, en concreto Emerita y Norba en el convento Emeritense, Olisipo en el Scallabitano y Salacia en el Pacense. A pesar de ello el grupo más nutrido de los Flavii lusitanos se ubicaría en éstos (48\%), pero sólo gracias a la enorme aportación de los testimonios de Emerita Augusta. Por el contrario, la mayoría de los núcleos urbanos donde atestiguamos el gentilicio Flavius son núcleos a los que se ha adjudicado, si bien con distinto grado de certeza, un estatus de municipio flavio, y a los que, en todo caso, se les relaciona con la política romanizadora y urbanizadora de los Flavios en Lusitania: Caesarobriga ${ }^{12}$,

\footnotetext{
J. Salas Martin/J. Rosco Madruga, “Epigrafía latina votiva de Santa Lucía del Trampal, I (Alcuéscar, Cáceres)", Norba, 13, 1993, 63-64.

8 Sobre la riqueza de la explotación agropecuaria y minera en la zona de Los Arribes, M. SALINAS DE FRIAS, "Onomástica y sociedad...", 288, y en general, idem, “Problemática socioeconómica del mundo indígena lusitano", El proceso histórico de Lusitania oriental en época prerromana y romana, Mérida, 1992; J. MANGAS, "Ciudades antiguas de la provincia de Salamanca (s. III a.C.-Diocleciano)", Actas del I Congreso de Historia de Salamanca, I, Salamanca, 1992, 264-265, no ve factible que este enclave fuera un centro político-administrativo, a pesar de la abundancia de epigrafes que ha proporcionado.

9 J. DE Francisco, Conquista y romanización de Lusitania, Salamanca, 1989, 305.

10 Con protagonismo en la red viaria de la zona, cfr. J. AlARCÂO, Portugal Romano, Lisboa, $1974,100$.

A. Tovar, Iberische Landeskunde. Band 2. Lusitanien, Baden-Baden 1976, 218-219 (Dipo); J. Alarcâo, Portugal Romano, Lisboa, 1974, 83; Se trata de un área de explotación agropecuaria, en el caso de Serpa próxima a minas de cobre, cfr. J. DE FRANCISCO, Conquista y romanización de Lusitania, Salamanca, 1989, 330, 332, $336 n .^{\circ} 40$.

12 Se trata de un municipio flavio, cfr. J. DE Francisco, Conquista y romanización..., 352 y P. LE Roux, "Droit latin et municipalisation en Lusitanie sous l'Empire", Revisiones de Historia Antigua.II..., 252.
} 
Turgalium ${ }^{13}$, Augustobriga ${ }^{14}$ y Ciudad Rodrigo ${ }^{15}$ en el convento Emeritense, la civitas Igaeditanorum ${ }^{16}$, Collippo ${ }^{17}$, Conimbriga ${ }^{18}$ y Aeminium ${ }^{19}$ en el convento Scallabitano, y Balsa ${ }^{20}$ y Mirobriga ${ }^{21}$ en el convento Pacense. En éstos situamos un grupo significativo (37\%) de los Flavii lusitanos, resultando esta aportación más minoritaria en el convento Emeritense, debido al aplastante conjunto de Emerita, y con más peso en el convento Pacense y sobre todo en el Scallabitano ${ }^{22}$. Finalmente, un pequeño grupo de Flavii (15\%) se localizan en núcleos poblacionales secundarios, privados

13 P. LE Roux, “Droit latin et municipalisation en Lusitanie sous l'Empire», Revisiones de Historia Antigua.II..., 252- 253 le considera de status no precisado, pero afectado por el derecho latino flavio.

14 J. DE Francisco, Conquista y romanización..., 353 le considera municipio flavio, y $P$. LE Roux, "Droit latin et municipalisation en Lusitanie sous l'Empire», Revisiones de Historia Antigua.Il..., 252-253 como un núcleo de estatus no precisado, si bien afectado por el derecho latino flavio.

15 J. DE Francisco, Conquista y romanización..., 354, y J. ManGas, «Derecho latino y municipalización en la Meseta superior», Teoria y práctica del ordenamiento municipal en Hispania, Revisiones de Historia Antigua, II, Vitoria, 1996, 235, otorgan la condición de municipio flavio a Ciudad Rodrigo. P. LE Roux, "Droit latin et municipalisation en Lusitanie sous l'Empire", Revisiones de Historia Antigua.ll..., 252, lo considera un núcleo de estatus no precisado.

16 Tiene la categoría de municipio flavio, J. DE FRANCISCO, Conquista y romanización..., 353 y $P$. LE ROUx, "Droit latin et municipalisation en Lusitanie sous l'Empire», Revisiones de Historia Antigua. II..., 252-253.

17 Se trata de un municipio flavio, cfr. J. DE Francisco, Conquista y romanización..., 353, y P. LE Roux, “Droit latin et municipalisation en Lusitanie sous l'Empire», Revisiones de Historia Antigua./l..., 252-253.

18 J. DE FRANCISCO, Conquista y romanización..., 353 le considera municipio tlavio, y P. LE Roux, "Droit latin et municipalisation en Lusitanie sous l'Empire", Revisiones de Historia Antigua.II..., 248-250 y 252-253 como un núcleo de estatus no precisado, si bien afectado por el derecho latino flavio.

19 P. LE Roux, «Droit latin et municipalisation en Lusitanie sous l'Empire», Revisiones de Historia Antigua.II..., 252- 253 le considera un núcleo de estatus no precisado, si bien afectado por el derecho latino flavio.

20 Se trata de un municipio flavio, cfr. J. DE Francisco, Conquista y romanización..., 352, y P. LE ROux, "Droit latin et municipalisation en Lusitanie sous l'Empire», Revisiones de Historia Antigua.II..., 252-253.

21 Se trata de un municipio flavio, cfr. J. DE Francisco, Conquista y romanización..., 352, y P. LE Roux, “Droit latin et municipalisation en Lusitanie sous l'Empire”, Revisiones de Historia Antigua.11..., 252-253.

22 En el convento Emeritense un $23 \%$ de los portadores del nomen Flavius se situan en núcleos urbanos de posible promoción flavia, frente a un $71 \%$ que lo hace en núcleos de promoción pre-flavia, especialmente en la capital, Emerita. En el convento Pacense el $40 \%$ de los Flavii se localizan un núcleos de posible promoción flavia, frente a un $30 \%$ que lo hacen en núcleos de promoción pre-flavia. Finalmente, en el convento Scallabitano un $57 \%$ de los portadores del nomen Flavius se sitúan en núcleos de posible promoción flavia, frente a sólo el $22 \%$ de ellos que se ubican en núcleos de promoción pre-flavia. 
de promoción jurídica, pero con una economía dinámica y buena situación con respecto a la red viaria ${ }^{23}$.

La obtención de resultados absolutamente concluyentes a partir del análisis de la distribución cronológica de los documentos estudiados se ve dificultada por la imposibilidad de contar con una datación suficientemente precisa para casi la mitad de los testimonios recogidos ${ }^{24}$. Ahora bien, parece claro que el gentilicio Flavius hace su aparición en Lusitania ya en época preflavia (12\%), en los conventos Emeritense y Scallabitano, en núcleos de estatus privilegiado, como son Emerita ${ }^{25}$ y Olisipo ${ }^{26}$, y en el área de Turgalium ${ }^{27}$, portado por emigrantes itálicos o sus descendientes, o bien por ciudadanos de origen provincial, uno de ellos veterano militar. Sin embargo, el grueso de los Flavii se distribuye en la provincia desde finales del s. I y a lo largo del s. II d.C. (34\%). En este período están bien constatados en Emerita, donde algunos de estos individuos evidencian con claridad una promoción gracias a la política romanizadora Flavia, e incluso llegan a insertarse en las élites municipales ${ }^{28}$, abundando

23 Casos ya mencionados de Hinojosa de Duero (Salamanca), el santuario de Ataecina de Alcuéscar (Cáceres), Elvas (Portalegre), Serpa (Bajo Alentejo), el entorno de Penamacor (Castelobranco) y Lamego (Viseu).

24 En un $40,5 \%$ de los epigrafes recogidos hemos de dar una datación muy amplia, en los ss. II-III d.C., y todavía en otro $7,5 \%$ en los ss. 1-III d.C., siendo difícil acotar más esta cronología. Los Flavii recogidos en estos documentos son básicamente indígenas romanizados y/o individuos de origen servil: AE 1983, 480 en Lamego; ILER 5061, AE 1996, 858, 859 y AE 1967, 138, en la civitas Igaeditanorum; CIL II 344, zona de Collippo; AE 1985, $531=$ HEp 3 , 473 y AE 1962, 192 = ILER 121, ambas del entorno de Penamacor; AE 1967, 209, en Campolugar (Cáceres), pero procedente de Emerita; AE 1905, 24; ILER 4386, 3455, 6130; HEp 3. 96, todas ellas de Emerita; EE 9, 116, en Norba; CIL II 5323, en Caesarobriga; CIRS 33, en Ciudad Rodrigo; CIL II 6254.14 en Balsa y DE 598 en Elvas.

25 AE 1967, 190, C. Flavius C.f. Pap(iria) Sabinus, individuo de origen dificil de precisar, pero podria ser un descendiente de los colonos itálicos asentados en la colonia.

26 AE 1979, 334, G. Flavius L.f. Gal(eria) Toncius en Assafora (Lisboa), un provincial de origen indigena tempranamente beneficiado por la ciudadanía; CIL II 266, [-] Flavius M.f. Gal(eria), aquilifer legionis /l en Terrugem (Sintra, Lisboa), un veterano asentado en el entorno de Olisipo, probablemente natural de la zona, cfr. J. DE Francisco, Conquista y romanización..., 149, 171.

27 VL $24=$ HEp 5, 193, C. Flavius A.f.

28 En Emerita el gentilicio aparece incrustado ya en las últimas décadas del s. I en la élite municipal, como refleja un epigrafe hallado en Salacia: CIL II $32=$ DE 183, Flavia L.f. Rufina, emeritensis, flaminica provinciae Lusitaniae item coloniae Emeritensis perpetua et municipii Salaciensis. Es posible que esta flaminica sea miembro de una familia que recibió la ciudadania con Vespasiano (cfr. R. ETIENNE, Le culte impèrial dans la Péninsule lbérique d'Augusto a Dioclètien, Paris, 1958, 166-167), pero no debemos olvidar que en Emerita el gentilicio Flavius aparece ya en ciudadanos romanos de época pre-flavia; sin embargo, también conocemos en la colonia desde finales del s. I y durante el s. II d.C. Flavii de origen provincial que 
sobre todo los indígenas romanizados junto a algún liberto, e igualmente se constatan en los conventos Scallabitano y Pacense, donde el gentilicio es portado por indígenas romanizados e individuos de origen servil ${ }^{29}$. Por el contrario, es muy inferior su presencia en momentos más tardíos, Ss. III-IV d.C. $(6 \%)^{30}$. Esto contrasta con lo constatado en Bética y la Tarraconense, donde el gentilicio Flavius muestra una pervivencia significativa en el período tardoantiguo (sS. IV-VI d.C.), en alguna ocasión asociado a miembros de las altas jerarquías de la administración imperial, pero sobre todo en fuentes de carácter paleocristiano en la Bética ${ }^{31}$, y en

deben su promoción a la dinastía Flavia, cfr. CIL II 505, T. Flavius Sexticius, hijo de lanuarius Venusti f. emeritensis; FRA taf.72A, T. Flavius Amethystus, su esposa Flavia Firmana y su hijo $T$. Flavius Beryllus, posiblemente libertos acomodados de una familia que obtuvo la ciudadanía bajo los Flavios; CIL II 521, Flavia Flavina, una indígena romanizada, madre de Marcus Rufin(i)us Albinus, taporus; ILER 4984, M. Flavius Rufus y su liberto M. Flavius Primus. En otros puntos del convento Emeritense también localizamos el gentilicio desde finales del s. I y a lo largo del s. II d.C., portado sobre todo por indígenas romanizados: Hinojosa de Duero (CIRS 127, Flavia Flavi $f$ ), Caesarobriga (CIL II 908, Flavia Caeli Flavi f.), Augustobriga (RH 658, Flavia Rufina augustobrigensis; $\mathrm{RH} 481$, Flavius), y en un santuario de Ataecina de Alcuéscar (ÑQ 11, Flavia Patricia).

29 En el convento Scallabitano, en el mismo periodo encontramos a los Flavii en Aeminium (CIL II 395, G. Flavius Baeticus, quizá de origen servil), Conimbriga (CIL II 366, Flavius Flavus y su hija Flavia, indigenas romanizados; RE 49, Flavius?, otro indigena romanizado), Olisipo (CIL II 179, Flavia Tyche, quizá una liberta de origen oriental) y Collippo (EE 9, 28, Flavia Maxsima-sic, una indígena romanizada cuyo hijo podría portar la tribu Quirina, lo que situaría la promoción de la familia en epoca Flavia). Finalmente, en el convento Pacense contamos con testimonios para este período en Serpa (ILER 3210, Flavia, una indigena romanizada) y Balsa (CIL II 5172, Quintus Flavius Seranus; CIL II 5168, C. Flavius Relatus, dos individuos de posible origen servil, cfr. J. D'ENCAANAÇAO, Inscriçôes romanas do conventus pacensis, Coimbra, 1984, 143, 138.

30 Es posible que buena parte de los documentos cuya datación los sitúa en un período amplio formado por los ss. II-111 d.C. haya que ubicarlos más bien hacia los finales del la segunda centuria y primera mitad del s. III d.C. En todo caso, en el s. III d.C. el nomen Flavius se atestigua con seguridad ên Salacia (DE 191, Flavia Lupercilla), Mirobriga (CIL II 23, Flavia Titia) y Serpa (AE 1986, 278 Adn. Flavius? Severus), todas ellas en el convento Pacense, y quizá en Lamego (Viseu), en el convento Scalabitano. Los documentos tardoantiguos son realmente excepcionales, contando sólo con un epigrafe del s. Iv d.C. (AE 1975, 472, Tib. Flavius Laetus, comes, senatorial, quizá de origen extraprovincial, cfr. A.H.M. JONES/J-R- MARTINDALE/J. MORRIS, The Prosopography of the Later Roman Empire, I, Cambridge, 1971, 492, no indica su origen).

${ }_{31}$ Se trata sobre todo de documentación paleocristiana: En Montilla (Córdoba), CIL $I^{2} .5$, 545; en Castro del Río (Córdoba), CIL $\|^{2} .5,404-405$; en Igabrum, CIL $\|^{2} .5,334$ y 335 ; en Ostippo, CIL II'5, 992E; En Acinipo, CIL II 6253.11; Sobresale también Flavius Chionius, episcopus astigitano?, en varios lateres y tegulas cristianas del s. $\vee$ o vi d.C., cfr. CIL $\|^{2} .5$, $56 \mathrm{~A}-\mathrm{B}, 206,461-463,559,923,980,1000,1349-1350$, en diversos puntos de la provincia de Jaén, Córdoba y Sevilla; También CIL $\mathrm{Il}^{2} .7,276$, un vir clarissimus, comes y praeses provinciae Mauretaniae Caesarensis, individuo seguramente de origen cordubense, en un documento de Corduba de finales del s. Iv o inicios del s. $v$ d.C. 
documentos tardíos de indígenas romanizados en el norte y noroeste peninsular en la Tarraconense ${ }^{32}$.

En el aspecto onomástico los Flavii de Lusitania se manifiestan como un grupo homogéneo, de manera que son portadores de una antroponimia altamente latinizada, con raras pervivencias de onomástica indígena, cuyos esquemas se ajustan en su mayoría a los propios de los ciudadanos romanos. Entre los varones resultan ligeramente más numerosos los esquemas de duo nomina (47\%) frente a los de tria nomina (33\%). En un pequeño grupo de casos (20\%) los varones Flavii portan el gentilicio sin el acompañamiento del cognomen, lo que responde a varias razones: una omisión del mismo ${ }^{33}$, al deterioro del epígrafe ${ }^{34}$, a una cronología temprana del documento ${ }^{35}$, y sólo en dos casos a una práctica onomástica de raíz prerromana ${ }^{36}$. Los tria nomina de los Flavii lusitanos son característicos del período altoimperial (ss. I-II d.C.) ${ }^{37}$, y aunque contamos con algún caso extremadamente

32 CIL II 5683, Flavius Avitus, en Ruesga (Palencia), de comienzos del s. IV; CIL II 2918 , Flavia Sempronia, en Meakaur/Morga (Vizcaya), s. Iv; AF 341, Flavius Fuscus, en Lodoselo (Sarreaus, Orense), en el s. V; AF 85, Flavius? Flavinus?, del s. IV o v, en Presqueira (Baños de Molgas, Orense); AF 335, Flavia Nusi (f.), en el Museo de Orense, del s. v; RIT 960, Flavius Zoticus, en un epigrafe paleocristiano de Tarraco, de finales del s. IV o comienzos del s. v; AF 355=HEP2, 847, Flavius Maternianus, un documento paleocristiano en Aquae Flaviae del s. $v$ d.C.; AF 204, Flavius, uno de los donantes de la iglesia de S. Pedro de Rocas (Orense), ya a finales del s. vi d.C. CIL II 2699, Flavius Strategius Apion en Oviedo, del 539 d.C., un consular del Imperio Bizantino, cfr. J.R. MARTINDALE, The prosopography of the Later Roman Empire, vol.Ill A, Cambridge, 1992, 96-98.

${ }_{33}$ Sería el caso de las filiaciones, en las que no es posible conocer el cognomen, pero que debió existir: AE 1967, 190, C. Flavius, filiación de C. Flavius Sabinus; CIL II 32, L. Flavius, filiación de Flavia Rufina; AE 1979, 334, L. Flavius, filiación de G. Flavius Toncius; CIL II 266, M. Flavius, filiación de [-J Flavius Quadratus. Estas filiaciones permitirian elevar la presencia del tria nomina entre los Flavii varones lusitanos hasta un $42 \%$. También resulta omitido el cognomen en el caso de los patronos de libertos cuya onomástica conocemos sólo a través de la de sus libertos, ILER 5061, Flavius/a?, patrono de los Flavii Gemellus, Lucrio y Carus.

34 AE 1967, 138, Flavius [---].

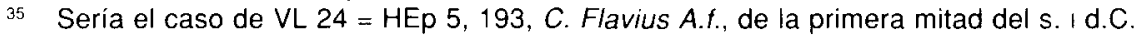

36 RE 49, Flavius? y RH 481, Flavius, en ambos epígrafes los individuos que aparecen a su alrededor portan esquemas antroponímicos de nombre único, a veces seguido de patronímico, de tradición indígena.

37 CIL II 266. [-] Flavius M.f. Gal. Quadratus, aquilifer legionis II, un veterano probablemente de origen hispano, en Olisipo, de época julio-claudia; AE 1979, 334, G. Flavius L.f. Gal. Toncius, un indigena romanizado del área de Olisipo, s. I d.C.; CIL II 395, G. Flavius Baeticus, en el área de Aeminium, de finales del s. 10 principios del s. II; AE 1967, 190, C. Flavius C.f. Pap. Sabinus, un ciudadano de Emerita, quizá de origen itálico, s. I d.C.; CIL II 505, T. Flavius Sexticius, en Emerita, finales s. I o comienzos del s. II; ILER 4964, M. Flavius Rufus y 
tardío, se trata de un individuo de altísimo rango, un senatorial ${ }^{38}$. En todo caso, los portadores de praenomen son ciudadanos romanos en su mayoría de origen provincial y a menudo de posición económica acomodada, entre los que encontramos patronos de libertos y dueños de esclavos, algún veterano militar, y varios libertos, alguno de nivel solvente. El praenomen más frecuente en el grupo gentilicio es el de $C$ (aius)/G(aius) $)^{39}$, siendo también significativa la presencia de $T$ (itus) ${ }^{40} y$ $M$ (arcus) ${ }^{41}$, y ya sólo puntualmente constatamos los de $L$ (ucius) ${ }^{42}$, A(ulus) ${ }^{43}, Q$ (uintus) y $T$ (iberius) ${ }^{44}$. Excepto $T$ (itus), $Q$ (uintus) y Tib(erius),

M. Flavius Primus, patrono y liberto, también en Emerita, de finales del s. I o primera mitad del s. II d.C.; FRA Taf. 72A, T. Flavius Amethystus y su hijo T. Flavius Beryllus, libertos acomodados de Emerita, de la primera mitad del s. II; ILER 4386, T. Flavius Eutiches, seguramente otro liberto, en Emerita, de la segunda mitad del s. II o principios del s. III d.C.; AE 1905, 24, C. Flavius Baeticus, conimbrigensis, dueño de un esclavo en Emerita, s. 11 o comienzos del s. III d.C.; En Balsa contamos con dos testimonios de individuos de origen servil en el s. II d.C., CIL $\| 5172=$ DE 85, Quintus Flavius Seranus, y CIL $\| 5168=$ DE 81, C. Flavius Relatus, liberto de alto nivel económico; En Norba, EE9, 116, M. Flavius Celsus, un indigena romanizado del s. "1 o principios del s. III d.C.

38 AE 1975, 472, Tib. Flavius Laetus, senatorial, en Emerita, s. IV d.C., cfr. A. H. M. JONES/J.-R. MARTINDALE/J. MorRIS, The Prosopography of the Later Roman Empire, I, Cambridge, 1971, 492, no indica su origen, quizá de procedencia extraprovincial.

${ }_{39}$ Los C./G. Flavii aparecen en Lusitania tempranamente, lo que no es de extrañar ya que el praenomen se vincula estrechamente a la onomástica personal de la dinastía JulioClaudia. Así se constata ya en época preflavia en Emerita y el área de Turgalium (AE 1967, 190; VL 24), posiblemente con un origen itálico, asi como en Olisipo (AE 1979, 334), tratándose en este caso de un ciudadano de origen provincial. Ya desde finales del s. I d.C. y en el s. II d.C. hallamos C/G Flavii en Aeminium (CIL II 395), Balsa (CIL II 5168, un liberto acomodado) y Conimbriga ( $A E$ 1905, 24), ciudadanos cuyas familias parecen haber promocionado su status juridico gracias a la concesión del ius latii de Vespasiano.

40 Los $T$. Flavii se localizan sólo en Emerita, a partir de época flavia y siempre en el período altoimperial. Portan una asociación de praenomen + nomen propia de la dinastía Flavia. Se trata de indígenas romanizados (CIL 11505 ) y libertos, aigunos acomodados (FRA Taf. 72A; ILER 4386), miembros de familias que alcanzaron la ciudadania bajo los Flavios.

${ }^{41}$ Los $M$. Flavii se remontan a la etapa preflavia, ya que a ellos pertenece el padre de un veterano de origen hispano, probablemente lusitano, del entorno de Olisipo, de época julioclaudia (CIL II 266). En el período altoimperial, a partir de época flavia, hallamos a los $M$. Flavii en Norba (EE 9, 116) y Emerita (ILER 4964), entre ciudadanos de origen provincial, en el caso de Emerita implicados en relaciones de dependencia.

${ }_{42}$ El praenomen Lucius aparece ya asociado al gentilicio Flavius al inicio de la etapa im. perial, en la filiación de un ciudadano provincial de promoción preflavia (AE 1979, 334), y pervive en una familia de la aristocracia de Emerita de finales dei s. I d.C. que debió de promocionar su estatus juridico gracias a la política de romanización flavia (CIL $\| 32=D E$ 183).

Después de este período no registramos más testimonios de los $L$. Flavii.

43 Sólo contamos con un A. Flavius (VL 24), datado en la primera mitad del s. I d.C., seguramente un individuo de procedencia itálica.

44 Ambos praenomina se constatan ya en el período postflavio: Quintus, que aparece en el epígrafe totalmente desarrollado, es portado por un niño de Balsa, quizá de origen servil, 
todos los demás hacen sus primeras apariciones vinculados al gentilicio Flavius ya en época pre-flavia. En cuanto a los varones portadores de duo nomina, se trata de un grupo constituído principalmente por indígenas romanizados y libertos que cronológicamente se sitúan en los ss. II-III d.C. ${ }^{45}$.

Por otro lado, las mujeres de la gens Flavia lusitana suelen acompañar el gentilicio de un cognomen, en un esquema de duo nomina propio de las ciudadanas romanas. Sin embargo, en algunos pocos casos, igual que constatamos entre los varones, éstas ostentan el gentilicio como nombre único, en ocasiones seguido de un patronímico, esquema onomástico de tradición indígena ${ }^{46}$. Finalmente la filiación, tribus y origo son elementos que forman parte del esquema antroponímico de los Flavii lusitanos de forma muy puntual. La filiación de estilo romano aparece sólo en ciudadanos del s. I d.C. ubicados en importantes ciudades privilegiadas, como son Olisipo y Emerita ${ }^{47}$, y en esta misma línea, la mención de la tribus se circunscribe únicamente a ciudadanos romanos de origen provincial y promoción preflavia ${ }^{48}$. El patronímico, mención del nombre del padre de tradición indígena, se halla en algunos indígenas romanizados del s. II o principios del s. III d.C. ${ }^{49}$. La origo tampoco es frecuente, pero en todo caso los escasos testimonios se asocian tanto a varones como a mujeres, y suelen hacer

probablemente del s. 11 o inicios del s. III d.C. (CIL II 5172), y Tiberius es el praenomen de un senatorial bajoimperial, quizá de origen extraprovincial (AE 1975, 472).

45 En la civitas Igaeditanorum contamos con varios libertos (AE 1996, 858 y 859; ILER $5061)$ y quizá un indígena romanizado (AE 1967, 138). También en Emerita contamos con varios posibles libertos (AE 1967, 209; ILER 3455) y un individuo de origen incierto (ILER 6130). Además CIL II 344, un indigena romanizado del territorio de Collippo; CIL II 6254.14, dueño de un esclavo en Balsa; CIL II 366, un indígena romanizado de Conimbriga; ILER 121 y AE 1985,531 ), dos indígenas romanizados del entorno de Penamacor; AE 1983, 480, una familia de indígenas romanizados en Lamego; AE 1986, 278 Adn, otro indígena romanizado del entorno de Serpa y CIRS 33, indigena romanizado de Ciudad Rodrigo.

46 CIL II 908, Flavia Caeli Flavi en Caesarobriga; CIRS 127, Flavia Flavi en Hinojosa de Duero (Salamanca); ILER 3210, Flavia, en Serpa; CIL II 366, Flavia, hija de Flavius Flavus y Antonia y hermana de Antonius Flavinus en Conimbriga, siendo peculiar en este documento que sólo las mujeres de la familia ostenten un único nombre.

47 Una dama de la aristocracia de Emerita (CIL II 32) y tres varones, portadores a su vez también de tribus (CIL II 266 y AE 1979, 334 en la zona de Olisipo y AE 1967, 190 en Emerita).

48 Se trata de dos testimonios de la Galeria procedentes del área de Olisipo (CIL II 266 y AE 1979, 334) y uno de la Papiria procedente de Emerita (AE 1967, 190).

49 CIL II 908 en Caesarobriga (Flavia Caeli Flavi); CIRS 127 en Hinojosa de Duero (Salamanca) (Flavia Flavi); CIRS 33 en Ciudad Rodrigo (Flavius Eligius Flavini et Flaccillae) y AE 1983, 480 en Lamego (Flavius? Paratus? Parati?). 
patente un desplazamiento del individuo con respecto a su lugar de procedencia ${ }^{50}$.

Una amplia mayoría (74\%) de los cognomina que acompañan al gentilicio Flavius en Lusitania son latinos. Éstos presentan un carácter variado y ninguno de ellos se repite en un número realmente significativo de individuos. Como excepción, contamos con algunos casos en los que un segundo gentilicio hace las veces de cognomen ${ }^{51}$, como Flavia Titia, T. Flavius Sexticius y Flavius Turius Felix ${ }^{52}$. Además, son raros $(8 \%)$ los cognomina indígenas, apenas presentes en la gens ${ }^{53}$, a pesar de que una gran parte de los Flavii lusitanos son precisamente individuos de origen provincial. Los antropónimos griegos, aunque también minoritarios, gozan de mayor entidad entre los miembros de la gens (18\%). Se localizan en los Ss. II-III d.C., sobre todo en Emerita y en menor medida en Olisipo y la civitas Igaeditanorum, en todo caso núcleos urbanos de importante entidad. En cuanto a la condición social de sus portadores, habida cuenta de la estrecha relación entre la onomástica griega y el origen servil ${ }^{54}$, da la

50 AE 1905, 24, C. Flavius Baeticus conimbrigensis en un epígrafe de Emerita; CIL II 32 , Flavia Rufina emeritensis en un documento de Salacia; $\mathrm{RH} 658$. Flavia Rufina augustobrigensis en un epigrafe hallado en Villar del Pedroso (Cáceres), al este de Talavera la Vieja (Augustobriga).

51 Este hecho no es muy frecuente, pero sí está bien atestiguado en la onomástica personal del Occidente Romano, cfr. J. M. ABASCAL PALAzón, Los nombres personales en las inscripciones latinas de Hispania, Murcia, 1994, 59, para Hispania o H. Gallego Franco, Prosopografía, Onomástica y Sociedad en el Imperio Romano. Las provincias de Rhaetia, Noricum, Pannonia Superior e Inferior, Valladolid, 1996, (microficha), 1982-2016, para las provincias alto-medio Danubianas.

52 CIL II 23, en Mirobriga, s. II d.C.; CIL II 505, en Emerita, fin s. 1 o comienzos s. II d.C.; AE 1985, 531, en Penamacor, ss. II-III, aunque en este caso podríamos ver en Turius un antropónimo de origen indígena, cfr. A. Holder, Alt-Celtischer Sprachschatz, vol. 11, Graz, 1962, 2000-2001; señalamos también, sobre este último documento, que HEp 3, 473 lee Titius Felix en vez de Turius Felix.

53 El testimonio más temprano es el de AE 1979,59, 334, G. Flavius Toncius, un ciudadano romano de origen ingenuo del área de Olisipo, s. I d.C. Más tardíos son AE 1967, 209, Flavia Ambasia, quizá una liberta, en un documento procedente de Emerita y hallado en Campolugar (Cáceres), segunda mitad del s. II o principios del s. III d.C.; AE 1983, 480, Flavius/a? Tongius/a?, un indígena romanizado, en Lamego, quizá de finales del s. II o s. III d.C.; CIRS 33, Flavius Eligius, otro indígena romanizado, en Ciudad Rodrigo, en un documento quizá del s. II o principios del s. III d.C. A. HOLDER, Alt-Celtischer Sprachschatz, 1, Graz, 1961, 116 (Ambasia); A. Holder, Alt-Celtischer..., II, Graz, 1962, 1887 (Tongius); M. PALOMAR LAPESA, La onomástica personal prelatina de la antigua Lusitania, Salamanca, 1957, 105 (Toncius/Tongius), 72 (Eligius).

54 H. Solin, Beitrage zur kenntnis der Griechischen Personennamen in Rom, Helsinki, 1971, 159. Cfr. para Hispania, A. Lozano, «La transmisión de los antropónimos griegos en la 


\section{impresión de que estamos frente a un grupo de libertos o sus des- cendientes ${ }^{55}$.}

El análisis de los lazos familiares de los Flavii lusitanos, en aquellos casos en que la documentación epigráfica lo permite, revela relaciones con varios grupos gentilicios. Se trata mayoritariamente de gentilicios de origen itálico, algunos de ellos ampliamente difundidos en Lusitania y en Hispania en general y vinculados a las primeras etapas de la romanización, como Valerius ${ }^{56}$, Cornelius? ${ }^{57}$, Aemilius ${ }^{58}$, Antonius ${ }^{59}, y$

epigrafía latina de Hispania», Actas del $\vee$ Coloquio sobre lenguas y culturas prerromanas de la Península lbérica, Noviembre, 1989, Salamanca, 1993, 361-409.

55 En Emerita: HEp 3, 96, Flavia Elpis; FRA Raf.72A, T. Flavius Amethystus y su hijo T. Flavius Beryllus, seguramente unos libertos acomodados; la esposa del primero, Flavia Firmana, porta el mismo gentilicio, de manera que debian ser libertos de la misma familia; ILER 4386, $T$. Flavius Eutyches, cuya esposa Flavia lustina porta también el mismo gentilicio. AE 1967, 209, Flavius Summachus, un epigrafe de Campolugar (Cáceres), procedente seguramente de Emerita; su esposa Flavia Ambasia lleva idéntico gentilicio. ILER 3455, (Flavius) Menander, hijo de Flavius Neapolitanus y (Flavia) Sabina; entendemos que los dos omiten el gentilicio por ser el mismo que el de Neapolitanus, y debían ser una familia de libertos. En Olisipo, CIL II 179, Flavia Tyche, una cernophora del culto a la Magna Mater, podría ser una liberta, lo que no excluye tampoco una posible procedencia oriental de la misma. En la Civitas Igaeditanorum tenemos a AE 1996, 859, Flavius Ariston, el único liberto que explicita su estatus, un liberto público de los Igaeditani, y también AE 1996, 858, Flavius Zosimus. Cfr. H. Solin, Griech Personennamen in Rom, Berlin, 1982, 1205 (Elpis), 1135 (Amethystus), 1136 (Beryllus), 796, 1362 (Eutyches), 969, 1368 (Summachus), 244 (Menander), 441, 1341 (Tyche), 721 (Ariston), 819 (Zosimus).

56 EE9, 28, Flavia Maxsima y su hijo Valerius Maxsimus, seguramente dos indigenas romanizados del territorio de Collippo, s. II d.C., aunque las líneas del documento correspondientes al nombre de hijo difunto son de difícil lectura. Valerius $(H$. SOLIN/O. Salomies, Repertorium nominum et cognominum Latinorum, Hildesheim/Zürich/New York, 1988, 197) es el segundo gentilicio más frecuente de la epigrafía hispanorromana, constatado sobradamente por todo el territorio lusitano, cfr. J. M. ABASCAL PALAZón, Los nombres personales en las inscripciones latinas de Hispania, Murcia, 1994, 232-244.

57 HEp3, 96, Flavia Elpis y su marido C(ornelius?) Urbicus, quizá una pareja de libertos de Emerita, ss. I--II d.C. Los Cornelii (W. ScHulzE, Zur Geschichte Lateinischer Eigennamen, Berlín, 1966, $445 \mathrm{~S}$.) constituyen el tercer grupo gentilicio más numeroso de Hispania romana, donde se implanta ya con la llegada de los Scipiones; en Lusitania se constatan sobradamente, en especial en Emerita, y también en Turgalium, Norba, Caesarobriga, Pax lulia, Salacia, Ebora, Olisipo y su entorno, Collippo e Igaedis, cfr. J. M. ABASCAL PALAZON, Los nombres personales en las inscripciones latinas de Hispania, Murcia, 1994, 116-125.

58 CIL II 5168, C. Flavius Relatus y su esposa Aemilia Chaeris, una pareja de probable origen servil, al menos la mujer, en el territorio de Balsa, segunda mitad del s. II. Los Aemilii (W. Schulze, Zur Geschichte..., 69, 295, 443, 454) constituyen el cuarto gentilicio más frecuente de Hispania romana, y no son raros, por tanto, en Lusitania, donde, además de en Balsa y su entorno, se les encuentra en Emerita, Caurium, varios puntos de la provincia de Caceres, en Viseu, Conimbriga, Igaedis, el área de Olisipo, Scallabis, Myrtilis, y la zona de Pax lulia, cfr. J. M. Abascal Palazón, Los nombres personales..., 67-52.

59 CIL II 366. Flavius Flavus y su esposa Antonia, con dos hijos, Flavia y Antonius Flavinus, una familia de indigenas romanizados de Conimbriga, s. II d.C. Antonius (W. ScHULzE, 
otros mucho menos frecuentes, como Lucilius ${ }^{60}$, Aufidius ${ }^{61}$ y Trebius ${ }^{62}$. Iulius es el único nomen de tipo imperial con los que los Flavii establecen lazos, lo que no es raro, ya que se trata del grupo gentilicio más numeroso de Hispania, extendido así mismo ampliamente por todo el territorio lusitano ${ }^{63}$. Finalmente, los Flavii manifiestan lazos con gentilicios propios de indígenas romanizados, casos de Rufinius ${ }^{64} \mathrm{y}$ Allius ${ }^{65}$. Ahora bien, estos vínculos entre familias se producen a un nivel modesto, implicando a indígenas romanizados e individuos de origen servil. En este sentido, encontramos también entre los Flavii lusitanos parejas con idéntico nomen, situación que seguramente responde al origen servil de ambos miembros de éstas, máxime cuando

Zur Geschichte..., 124) se encuentra en el grupo selecto de los diez gentilicios de mayor presencia en Hispania romana, bien atestiguado en Lusitania, especialmente en el área de Olisipo y de Scallabis, y en Emerita, y también se atestigua en Caesarobriga, Augustobriga, Norba, Turgalium, la zona de Conimbriga y Aeminium, Collippo, Ebora, el entorno de Pax lulia, cfr. J. M. ABASCAL PALAzón, Los nombres personales.., 79-82.

60 CIL II 23, Flavia Titia y su hija Lucilia Lepidina en Mirobriga, s. III d.C. No parece haber otros testimonios de los Lucilii (W. ScHulzE, Zur Geschichte..., 166, 442A, 450) en Lusitania, siendo un nomen también poco frecuente en la Bética y la Citerior, cfr. J. M. ABASCAL, Los nombres personales..., 175.

6. ClL II 344, Flavius Avitus, seguramente un indígena romanizado, y Aufidia [--], que debe ser su mujer, en el territorio de Collippo, ss. II-III. Es muy escasa la presencia de los $A u$ fidii (W. Schulze, Zur Geschichte..., 203, 269, 427, 481) en Lusitania, habiéndose localizado casos puntuales del gentilicio en Sellium (Tomar?) y en Porto de Mos (Leiría), no lejos del área de Collipo, asi como en Oliva de Plasencia (Cáceres), cfr. J. M. ABASCAL, Los nombres personales..., 89.

62 ILER 6130, Flavius Satrianus y su esposa Trebia Compse, quizá una liberta, en Emerita, ss. II-III d.C. Trebius (W. Schulze, Zur Geschichte..., 246,375, 468, 480) es un gentilicio poco frecuente en la epigrafía hispanorromana, y en Lusitania contamos con un puñado de testimonios, además de en Emerita, en Norba y algunos puntos de la provincia de Cáceres, y en Terena (Alandroal, Evora), cfr. J. M. ABASCAL, Los nombres personales..., 230-231.

63 DE 191, Flavia Lupercilla y su hijo /ulius Maximus, territorio de Salacia, s. III d.C. J. M. ABASCAL, Los nombres personales..., 151-163.

${ }^{64}$ CIL II 521, Flavia Flavina y su hijo M. Rufin(i)us Albinus, dos indigenas romanizados, en Emerita, s. ॥ d.C. Parece tratarse de un gentilicio derivado de un cognomen, Rufinus, práctica onomástica propia de indigenas romanizados del Occidente Romano en los ss. II-III d. C., cfr. G. ALFÖLDY; "Notes sur la relation entre le droit de cité et la nomenclature dans l'Empire romain", Latomus, XXV.1, 1966, 45-46.Precisamente Rufus y Rufinus son dos de los cognomina latinos más frecuentes de la epigrafía hispanorromana, ampliamente extendidos en territorio lusitano, cfr. J. M. ABASCAL, Los nombres personales..., 31, 485-490.

65 CIRS 33, Flavius Eligius y su esposa Allia Avita, indígenas romanizados, en Ciudad Rodrigo (Salamanca), S. II-CII. El gentilicio Allius (W. SCHULZE, Zur geschichte..., 423) no es muy frecuente en la epigrafía hispanorromana, aunque sí contamos con testimonios en Lusitania, especialmente en Conimbriga, Aeminium y Emerita, y tambièn se ha localizado en la localidad salmantina de Hinojosa de Duero, cfr. J. M. ABASCAL PALAZÓn, Los nombres personales..., 75. Sobre su homónimo indígena, M. PALOMAR LAPESA, La onomástica personal..., 30. 
uno de ellos suele ser portador de un onomástico griego ${ }^{66}$. Finalmente, resulta muy interesante la presencia de peregrinos sin derechos de ciudadanía en el ámbito familiar próximo de un pequeño grupo de nuestros Flavii lusitanos, reflejo en unos casos de un uso indebido del gentilicio y en otros de la promoción del estatus jurídico de la nueva generación frente a la anterior ${ }^{67}$.

También cabe analizar la posible prolongación de la huella onomástica de la gens Flavia en la provincia Lusitania bajo la forma de cognomina derivados -en concreto constatamos Flavianus/a ${ }^{68}$ y Flavinus/a ${ }^{69}$-, si bien este aspecto resulta complicado desde el momento en que estos cognomina en un esquema onomástico personal concreto pueden no proceder del gentilicio Flavius, sino derivar del cognomen latino Flavus/a ${ }^{70}$, que, además, aparece sólidamente arraigado en la onomástica personal lusitano-romana ${ }^{71}$, y en pocas ocasiones es

66 AE 1967, 209, Flavius Summachus y Flavia Ambasia; FRA Taf. 72A, T. Flavius Amethystus y Flavia Firmana; ILER 4386, T. Flavius Eutyches y Flavia lustina; ILER 3455 , Flavius Neapolitanus y Sabina.

67 En unos casos parece claro que el gentilicio se usó de forma inapropiada: CIL II 908, Flavia es hija de Caelius Flavus y Emuria, en Caesarobriga, s. III; CIRS 127, Flavia, hija de Flavus en Hinojosa de Duero (Salamanca), s. II; RE 49, Flavius?, hermano de Cilus y tío de Cilea, en Conimbriga, s. II. En otro es claro que el hijo consiguió la ciudadanía bajo los emperadores Flavios, mientras que su padre no promocionó su estatus jurídico: CIL II 505, T. Flavius Sexticius, hijo de lanuarius Venusti en Emerita, de finales del s. I o principios del s. II d.C. En cuanto a CIRS 33, de Ciudad Rodrigo (J. M. ABASCAL, Los nombres..., 140 y 351 da como lugar de hallazgo Ledesma, también en la provincia de Salamanca) es un caso de interpretación difícil, primero por la posición anómala del nomen en la persona de Eligius Flavius, hijo de Flavinus y Flaccilla, de los que no se registra el gentilicio, y cuya hija Flavina tampoco menciona el gentilicio; es posible, sin embargo, que éste simplemente se omitiera, aunque una datación exacta del epigrafe ayudaría a resolver el problema. Dejamos a un lado el documento AE 1983, 480, F(lavius)? Par(atus)?, hijo de P(aratus)? y padre de Ton(gius/a) en Lamego (Viseu), donde la lectura del gentilicio Flavius es demasiado precaria como para afirmar nada con seguridad. Cfr. A. Holder, Alt-Celtischer..., I, 1435 (Emuria), 675676 (Caelius), 1013-1014 (Cilus, Cilea); M. Palomar Lapesa, La onomástica personal..., 54 (Caelius), 72 (Emuria), 63-64 (Cilus, Cilea).

68 I. KaJANTO, The Latin Cognomina..., 35, 146 (Flavianus).

69 I. Kajanto, The Latin..., 36, 161=227 (Flavinus).

70 I. Kajanto, The Latin..., 18, 37, 64, 227 (Flavus).

71 En un núcleo reducido de testimonios el cognomen Flavus o su forma Flaus aparece acompañando a un gentilicio en el esquema onomástico de indígenas romanizados básicamente de los ss. $\mid$ y $\|$ d.C.: DE 445, L. Aurelius L.f. Flaus en Bencatel (Vila Viçosa), s. I; CIL II 366, Flavius Flavus en Conimbriga, s. II; CIL II 355, Laberia Q.f. Flava, en el territorio de CoIlippo, s. II; CIL II 5266, P. Valerius Flaus, miles legionis, en Emerita, primera mitad s. II; CIL II 787, T. Turellius Flavus, en Caurium, de finales del s. 10 s. II; ClL 11750 , Popillius Flavus, cerca de Norba, ss. II-inicio III; ILER 4408, Maurius Flavus, en Plasencia, ss. II-inicio III. Ahora bien, son más abundantes los testimonios epigráficos lusitanos en los que Flavus/Flaus aparece 
posible distinguir cuando estamos frente a la primera situación o frente a la segunda. De hecho, los resultados de un análisis comparativo de la distribución territorial de los cognomina Flavinus/Flavianus y del gentilicio Flavius en Lusitania, resultan poco concluyentes, ya que aunque en buena medida coincidan sus áreas de expansión, también coinciden en alto grado las de los antropónimos Flavius y Flavus ${ }^{72}$. En todo caso, Flavianus/a ${ }^{73}$ se constata sólo puntualmente en Lusitania, y parece propio de ciudadanos de situación socioeconómica privilegiada. Por el contrario, Flavinus/a es el cognomen derivado del que tenemos

como nombre único, con frecuencia seguido del patronímico, en los Ss. I-II d.C., siendo este un esquema antroponímico propio de peregrinos sin derecho de ciudadania. Un grupo importante de testimonios se concentran en el área de Caurium, Norba y Capera: CIL II 778, Flavus, filiación de Flavinus, HEp4, 231, FlavusTancini y AE 1985, 536, Flaus Marci, los tres en Caurium; ILER 3627 = HAP 1073, Flaus Naci, y CIL II 950, Flaus, deben proceder también de la región de Norba, Caurium y Capera; HEp5, 208, Flavus, marido de Cilea Flavi y HEp5, 207, Flavos, eques auxiliar, en el entorno de Plasencia (Cáceres); HEp3, 139, Flaus Duil-] o Dull-J, en Tejada de Tiétar (Cáceres); ILER 5970, Flaus, en Valencia de Alcántara (Cáceres). Próximos a esta zona, hallamos testimonios en Caesarobriga (Talavera de la Reina, Toledo), en concreto HEp5, 784, Flaus Presi y CIL II 908, Caelius Flavus, filiación de Flavia, y también en la provincia de Salamanca, CIRS 15, Flavus, en Béjar y CIRS 127, Flavus, filiación de Flavina, en Hinojosa de Duero. Poco más al norte, en el área zamorana del Sayago, tenemos CIL II 2620, Flavus Marceli $f$ y ClL II 2625, Mentina Flavi f. (J. M. ABASCAL, Los nombres personales..., 139 lee Ti. Flavi), ambos en Moral de Sayago. Ya en tierras portuguesas, en el borde norte de Lusitania, próximos al Duero tenemos los testimonios de AE 1996, 843, Flavus Pissiri, en S.Paio (Cinfâes), AE 1985, 519, Flavus, filiación de Flavina, en S. Joao da Fresta (Viseu), y HEp4, 987, Flaus Flavini, en Romariz (Feira, Aveiro); algo más al sur, los de ILER 136, Flavus Coroelleae y HEp4, 1053, Flavus Lepidi, en la zona de Aeminium, AE 1975, 481, Flavus Tuci en Conimbriga, AE 1994, 834, Flaus, en Escalos de Cima, cerca de Fundâo, y ILER 4854 y 973 , Flavus Reburri y Flaus, liberto de Sura, en la civitas Igaeditanorum. El testimonio más al sur sería el de HEp3, 479, Flaus Bouti, cerca de Ebora. En definitiva, resulta patente que el cognomen latino Flavus/a en Lusitania es propio de indígenas romanizados, individuos libres que sólo minoritariamente acceden a los derechos de ciudadanía, y que se sitúan preferentemente en la mitad norte de la provincia, en los conventos Scalabitano y Emeritense, siendo precisamente Emerita y Ebora, esta última en el covento Pacense, los lugares más meridionales donde se localiza el cognomen.

72 Los testimonios de estos cognomina derivados en Olisipo, la civitas Igaeditanorum, Conimbriga, Bobadella (Midôes), la franja norte provincial junto al Duero, Emerita, Caesarobriga y Ciudad Rodrigo (Salamanca) coinciden con la presencia del gentilicio Flavius en estas zonas. Por el contrario, no sería así en el caso de los testimonios de Myrtilis, Ebora, Caurium. Sin embargo, hay que tener en cuenta que en muchas de las localidades del primer grupo y su entorno también se constata el cognomen Flavus, que hallamos también en Ebora y en Caurium en el segundo grupo.

73 Así CIL II 314, Flavianus, cuyo gentilicio de omite, dueño del siervo Pultaris, cerca de Olisipo, ss. ॥-11!; DE 97, L. Helvius Flavianus, miembro de la aristocracia municipal de Myrtilis, s. II. Algo más al norte de Olisipo, en Colos (Alenquer), este onomástico aparece como nombre único en un documento funerario cristiano ya muy tardio, de finales del s. vi d.C.: $\mathrm{AE}$ 1925, 13, Flaviana. 
un mayor número de testimonios, y suele aparecer asociado a indígenas romanizados, al menos la mitad de ellos sin derechos de ciudadanía ${ }^{74}$, individuos libres de nivel socioeconómico modesto, aunque excepcionalmente hallemos entre ellos algún representante de las aristocracias locales ${ }^{75}$. En cuanto a la aparición de Flavius en posición de segundo gentilicio en Lusitania, contamos con un único caso que confirma la presencia del gentilicio en Caesarobriga ${ }^{76}$.

No son abundantes los datos socioeconómicos referidos a los Flavii lusitanos contenidos en nuestro grupo de fuentes epigráficas. En conjunto aparecen muy alejados de las élites provinciales y municipales. El ordo senatorial aparece representado por Tib. Flavius Laetus, comes en el marco de la administración provincial bajoimperial, pero probablemente de origen extraprovincial ${ }^{77}$. No contamos con representantes del ordo equestre, y las aristocracias y oligarquías municipales se mani-

74 En el área de Caurium conocemos HEP 4, 231, Flavinus, hijo de Flavus Tancini, s. I; CIL II 778, Flavinus Flavi, s. II; CIL II 5311. Flavinus, s. II. Aquí el cognomen aparece más bien relacionado con el onomástico flavus, y también es así en el borde norte de la Lusitania, aunque en esta zona próxima al Duero se atestigue el gentilicio Flavius en Lamego: AE 1985 , 519, Flavina Flavi, en S. Joao da Fresta (Viseu), s. II; HEP 4, 987, Flavinus, filiación de Flaus, en Romariz /Feira, Aveiro), ss. II- inicio III. También se localiza en la civitas Igaeditanorum (HAEP 1167, Flavinus, filiación de Tancinus, ss. 1-11) y en Caesarobriga (CIL II 5317, Flavinus, s. II), dos ciudades donde está atestiguado el gentilicio Flavius.

75 Acompañando a un nomen hallamos el cognomen Flavinus/a en Conimbriga, donde parece derivar del gentilicio Flavius, pero también se revela estrechamente relacionado con el onomástico Flavus, cfr. CIL II 366, Antonius Flavinus, del s. II, hijo de Flavius Flavus y Antonia, hermano de Flavia. También en Ciudad Rodrigo (Salamanca) parece derivar del gentilicio Flavius: CIRS 33, (Flavia?) Flavina, hija de Eligius Flavius Flavini $t$.,ss. II-inicio III. En Emerita, donde el gentilicio Flavius está bien constatado, conocemos los casos de CIL !I 521, Flavia Flavina, s. II; CIL II 511, Licinia Flavina, ss. I-III, aunque podría ser una mujer procedente de la Tarraconense (esposo Q. Licinius Paternus, interanniensis); EE9, 67, [-] Flavinus, liberto, ss. II-III, pero no hay prueba directa de que en estos casos el cognomen Flavinus derive de este gentilicio. Finalmente, este grupo se cierra con dos individuos de las élites municipales: CIL II 399, lulia Cn. f. Flavina, patrona de un liberto en Bobadella (Midôes), s. II, en un área del convento Scallabitano donde el gentilicio Flavius se halla bien constatado y en una localidad a la que se asigna el estatus de municipio flavio (P. Le Roux, "Droit Latin...", 252); ILER 5673 = HEP 6, 1039, C. Antonius C.f. Flavinus, sevir iunior, hastatus legionis /I Augustae, hijo de la flaminica perpetua lunia Verecunda, en Ebora, s. It, donde no se constata el nomen Flavius

76 CIL II 5323, Aurelia Flavia. Sobre la presencia del nomen Aurelius en Lusitania, cfr. H. Gallego Franco, "La gens Aurelia en Hispania ulterior a través de las fuentes epigráficas", Espacio, Tiempo y Forma, XIII, 2000, 351-387. Excluímos de esta situación CIRS 33, Eligius Flavius, que nos parece más un caso en que el gentilicio aparece en una posición anómala y donde Eligius sería un antropónimo de raíz indígena.

77 Cfr. A. H. M. Jones/J-R-MARTINDALE/J. MorRIS, The Prosopography of the Later Roman Empire, I, Cambridge, 1971, 492, no indica su origen. 
fiestan a través de la solitaria, pero brillante, figura de Flavia L.f. Rufina, emeritensis, flaminica provinciae Lusitaniae item coloniae Emeritensis perpetua et municipii Salaciensis ${ }^{78}$, dama que al menos nos atestigua la elevada promoción social que una rama de los Flavii alcanzó en Emerita, precisamente en época flavia, seguramente habiéndose beneficiado de la política de ciudadanía de Vespasiano ${ }^{79}$. Por lo demás, los miembros de la gens no alcanzan las magistraturas municipales u otros cargos públicos de relevancia, y su implicación en epigrafía honorífica o monumental es nula ${ }^{80}$. Apenas obtenemos datos sobre sus actividades profesionales y socioeconómicas, salvo la presencia de un grupo de patronos de libertos y dueños de esclavos ubicados en ámbitos urbanos muy concretos (Emerita, la civitas Igaeditanorum, Balsa) en los ss. II-II d.C., y cuya situación en el marco de las relaciones de dependencia indica un nivel socioeconómico desahogado ${ }^{81}$. Aunque no son desconocidos los libertos públicos ${ }^{82}$, la mayoría de los Flavii de origen servil son libertos privados, algunos de los cuales manifiestan una solvente economía ${ }^{83}$, pero sin que se conozcan las fuentes de su riqueza. La

78 CIL II $32=$ DE 183.

79 R. ETIENNE, Le culte impèrial..., 166-167, data el epigrafe en época flavia y señala que la familia debió acceder al derecho de ciudadanía con Vespasiano. Es probable que sea así, conocemos otro caso de promoción ciudadana en Emerita en este período, cfr. CIL II $505, T$. Flavius Sexticius que dedica a su padre lanuarius Venusti ( $f$.) emeritensis. Pero conviene también considerar que el gentilicio ya es conocido en Emerita en época preflavia (AE 1967, 190, C. Flavius C.f. Pap. Sabinus), y que no tenemos más testimonios de L. Flavii en Lusitania que la filiación de la flaminica Flavia Rufina y la filiación de un ciudadano provincial de promoción preflavia del área de Olisipo (AE 1979, 334, G. Flavius L.f. Gal. Toncius).

${ }^{80}$ De hecho sólo el senatorial Tib. Flavius Laetus, comes, (AE 1975, 472) es responsable de una obra de tipo monumental, la restauración del circo de Emerita, pero se trata sin duda de una iniciativa de marcado carácter oficial, en un contexto muy tardio (s. IV d.C.).

81 Asi ILER 5061, donde un Flavius/a sería patrono/a de tres libertos, los Flavii Gemellus, Lucrio y Carus, en la civitas Igaeditanorum; En Emerita contamos con ILER 4964, M. Flavius Rufus, patrono de M. Flavius Primus, y AE 1905, 24, C. Flavius Baeticus, dueño de Quintus; además CIL $\|$ 6254.14, Flavius Cornelianus?, dueño de Corinthus?, en un ánfora hallada en el territorio de Balsa. Ahora bien, la presencia de otros posibles libertos, aunque no expliciten su condición, refuerza la posición dominante de los Flavii como patronos de libertos precisamente en estos mismos lugares, con especial intensidad en Emerita (AE 1967, 209; HEp3, 96; FRA Taf.72A; ILER 4386, 3455), y de nuevo en el área de Balsa (CIL II $5168=$ DE 81) y en la civitas lgaeditanorum (AE 1996, 858).

82 AE 1996, 859, Flavius Ariston Igaeditanorum I.

33 FRA Taf. 72a, T. Flavius Amethystus, su esposa Flavia Firmana y su hijo Flavius Beryllus, que erigen su monumento funerario in hortis suis, en Emerita en la segunda mitad del s. II; ILER 4964, T. Flavius Primus que erige un monumento en memoria de su patrono y por la suya propia en Emerita, quizá a finales del s. 10 en la primera mitad del s. II d.C.; CIL II 5168, C. Flavius Relatus, cuya esposa Aemilia Chaeris porta un onomástico griego (H. Solin, 
única actividad profesional explicitada por los Flavii lusitanos, aunque tímidamente, es el servicio en el ejército, personificada tempranamente (primera mitad del s. I d.C.) en la persona del aquilifer [-] Flavius M.f. Gal. Quadratus ${ }^{84}$.

En cuanto al comportamiento religioso, los Flavii lusitanos son responsables de un grupo no muy abundante de dedicaciones votivas, en las que resultan mayoritarias aquellas orientadas a algunas de las deidades más importantes de panteón romano: luppiter Optimus Maximus, Venus Victrix Augusta, Mars y Hercules. El documento más temprano es el consagrado a Hércules, obra quizá de un emigrante romano-itálico en la primera mitad del s. I d.C. ${ }^{85}$. El Júpiter Capitolino, protector del Estado, recibe un monumento de gran calidad en época flavia, con un marcado carácter oficial, por parte de la flaminica provincial Flavia Rufina en Salacia ${ }^{86}$, y otras dos consagraciones ya posteriores en Norba ${ }^{87}$, y en Meimao (Penamacor, Castelobranco) ${ }^{88}$, obra de indígenas romanizados ${ }^{89}$. También la dedicante del monumento a Venus Victrix Augusta, Flavia Titia, parece ser una indígena romanizada de

Griech Personennamen..., 1297, 448), en el área de Balsa, en la segunda mitad del s. II, cfr. DE 81 p. 138 .

$84 \mathrm{CIL} \mathrm{II} \mathrm{266,} \mathrm{aquilifer} \mathrm{legionis} \mathrm{II;} \mathrm{J.} \mathrm{DE} \mathrm{Francisco,} \mathrm{Conquista} \mathrm{y} \mathrm{romanización...,} 149$ y 171 se inclina por su origen hispano, quizá incluso del área de Olisipo donde se halló el epígrafe.

85 VL $24=\mathrm{HEp5}, 193$, C. Flavius A.f., en Conquista de la Sierra (Cáceres), en el área de Turgalium.

${ }_{86} \mathrm{CIL} \|{ }^{2}=\mathrm{DE} 183$, que entiende la dedicación como oficial más que fruto de la devoción privada.

87 EE9, $116=\mathrm{AE}$ 1982, 454, M. Flavius Celsus. Cfr. C. Callejo Serrano, "Testimonios falsos en Lusitania", Homenaje a Sáenz de Buruaga, 1982, 329-337.

88 ILER 121= AE 1962, 192, Flavius? Albinus.

89 En las provincias hispanas las dedicaciones a luppiter son especialmente importantes en el noroeste peninsular, cfr. P. LE Roux/A. Tranor, "Rome et les indigènes dans le NordOuest de la Péninsule lbérique. Problèmes d'epigraphie et d'Histoire", MCV, IX, 1973, 218220. Teniendo en cuenta el carácter político de Júpiter como símbolo del Estado, es evidente que el aparato oficial romano se esforzó en implantar su culto precisamente en aquellas zonas donde menos había calado el conjunto de las estructuras administrativas, socioeconómicas y espirituales romanas. El culto a Júpiter Capitolino se convierte asi en un instrumento de cohesión entre los habitantes locales y Roma, y en un agente de transformación del entorno, cfr. M. A. Rabanal Alonso/A. Ferreras Valladares, "La Tríada Capitolina en el Conventus Asturum", Homenaje al Profesor Presedo, Sevilla, 1994, 623-624; J. Rodríguez Cortés, "Aspectos del culto a la Triada Capitolina en el valle del Guadalquivir», Studia Zamorensia Historica, VII, 1986, 413-414, 421-422; A. M. VÁzQUEz Hors, "La religión romana en Hispania. Estudio estadístico.l.", HAnt, 1977, 20; H. Gallego Franco, "Hispania y Pannonia: dos modelos de difusión del culto a la Tríada Capitolina", Hispania Antiqua, XX, 1996, 175-200. 
Mirobriga ${ }^{90}$, ya del s. III d.C. En cuanto a Mars, contamos con dos documentos procedentes de la civitas Igaeditanorum erigidos por individuos de nivel modesto ${ }^{91}$. En cuanto a la implicación de los Flavii en el culto imperial, ésta resulta bien probada ya a finales del s. I d.C. en Salacia y Emerita, lugares de actuación de la flaminica Flavia Rufina, ya mencionada. Sin embargo la vinculación de miembros de la familia al culto imperial no tiene continuidad, de manera que no es hasta el período bajoimperial (primer tercio del S. IV) cuando hallamos otro testimonio del culto imperial en Emerita, en la forma de un epígrafe monumental de clara inspiración oficial en el que el senatorial Tib. Flavius Laetus, comes de Hispania honra al emperador de turno ${ }^{92}$. En todo caso, estas iniciativas puntuales en lo que se refiere al culto imperial emanan de individuos profundamente insertados en las estructuras político-administrativas provinciales. Por otro lado, es muy limitada la incidencia de los cultos de raíz indígena prerromana entre los Flavii lusitanos, de manera que sólo dos divinidades de este tipo, Ataecina ${ }^{93}$ y los Vortiaecii ${ }^{94}$, son objeto de monumentos votivos en este grupo gentilicio, en los ss. ItIII d.C. En cuanto a los cultos orientales, sólo Flavia Tyche, sin duda una liberta de procedencia greco-oriental ${ }^{95}$, se implica en ellos, al aparecer como cernophora en una consagración a la Mater Deum Magna

90 CIL II $23=$ DE 147, in honorem Luciliae Lepidinae, su hija, con una intención mezcla de funeraria y votiva. El epíteto Augusta de la divinidad la relaciona con el culto imperial ( $R$. ETIENNE, Le culte impèrial..., 342), pero sin duda la motivación de la dedicación es eminentemente privada

91 AE 1996, 859, Flavius Ariston Igaeditanorum l:; AE 1967, 138, Flavius [---].

92 AE $1975,472$.

93 NQ 11, a la Dea Domina Turibrigensis Adecina Sancta dedica Flavia Patricia en un santuario de la divinidad en Sta. Lucia del Trampal (Alcuéscar, Cáceres). Debe ser también Ataecina la deidad honrada en AE 1986, 278 Adn., Dea Sancta, por Flavius? Severus, en Vila Verde de Ficalho (Serpa), ya que estos epítetos son aplicados en otras ocasiones a la diosa, cfr. J. D'ENCARNAÇAO, «Divindades indigenas da Lusitânia".., 18-19. Sobre esta divinidad de carácter infernal, cir. J. D'ENCARNAÇÂO, Divindades indigenas sob o dominio romano em Portugal, Lisboa, 1975, 110-117; J. M. Blázouez, Religiones en la España Antigua, Madrid, 1991, 60-62.

94 AE 1985, 531 = HEp3, 473, Flavius Turius Felix, en Penamacor (Castelobranco); cfr. sobre esta divinidad J. D'ENCARNAÇAO, "Divindades indigenas da Lusitânia", Conimbriga, 26 , 1987, 20, donde se la relaciona con Bandi Vorteaeceo. Pertenecería asi al grupo de divinidades asociadas a Fortuna y Tutela, cfr. J. D'ENCARNAÇÂO, Divindades indigenas sob o dominio romano em Portugal, Lisboa, 1975, 119-125, 137; J. M. BцÁzQuez, Religiones en la España Antigua. Madrid, 1991, 64-65

95 J. Alvar, "Los cultos mistéricos en Lusitania», // Congresso Peninsular de Historia Antiga, Coimbra, 1993, 813, señala la presencia frecuente de individuos de origen servil entre los devotos y cargos religiosos de estos cultos mistéricos, inclinándose por el origen oriental de éstos; de hecho parece que los libertos orientales lograban una cierta promoción social, presumiblemente también económica, desempeñando cargos religiosos en los cultos mistéricos. 
Idea Phrygia erigida en Olisipo en los comienzos del s. II d.C. ${ }^{96}$. Finalmente, cabe mencionar la inexistencia de documentación epigráfica de carácter paleocristiano entre los Flavii lusitanos, lo que supone un comportamiento diferente en relación a sus colegas de la Tarraconense y Bética, donde el gentilicio mantiene una presencia limitada pero significativa en documentación paleocristiana de cronología tardía (ss. IV-VI d.C.) ${ }^{97}$.

En conclusión, desde el punto de vista onomástico los portadores del nomen Flavius en Lusitania aparecen como un grupo altamente romanizado y latinizado, con mínimas pervivencias antroponímicas de raíz indígena, las cuales puntualmente pueden tomar forma de cognomina prerromanos, esquemas de nombre único o presencia de un patronímico. Por tanto, sus patrones onomásticos se ajustan en general a los propios de los ciudadanos romanos. Las mujeres suelen exhibir un esquema de nomen + cognomen, mientras que entre los varones son mayoritarios los esquemas de duo nomina, un grupo constituído básicamente por indígenas romanizados y libertos. A pesar de ello, entre los varones contamos también con un sólido grupo de esquemas de tria nomina que corresponden a un núcleo de ciudadanos romanos, en su mayoría de origen provincial y datación altoimperial, con una buena situación económica, entre los que encontramos patronos de libertos, dueños de esclavos, algún veterano militar y varios libertos, algunos de nivel acomodado.

Los Flavii lusitanos aparecen constituidos, en primer lugar, por un grupo mayoritario de individuos de origen provincial y ascendencia libre ${ }^{98}$, indígenas romanizados que adquirieron privilegios de ciudadanía,

96 El culto a Cibeles está bien atestiguado en Lusitania, cfr. J. ALVAR, “Los cultos mistéricos en Lusitania", // Congresso Peninsular de Historia Antiga, Coimbra, 1993, 801, 809.

97 En la Bética: CIL $\| 6253.11$; CIL $\left\|^{2} .5,545 ; \mathrm{CIL}\right\|^{2} .5,404-405 ; \mathrm{CIL} \|^{2} .5,334$ y $335 ; \mathrm{CIL}$ $I^{2} .5,992 E ;$ CIL II².5, 56A-B, 206, 461-463, 559, 923, 980, 1000, 1349-1350. En la Tarraconense, RIT 192, 960; AF 355=HEP2, 847; AF 204.

98 CIL II 366, Flavia y su padre Flavius Flavus; CIRS 33, Flavia? Flavina y su padre Eligius Flavius; CIL II 521, Flavia Flavina; DE 191, Flavia Lupercilla; EE 9, 28, Flavia Maxsima; NQ 11, Flavia Patricia; RH 658, Flavia Rufina; DE 183, Flavia L.f. Rufina; DE 598, Flavia Severa; CIL II 23, Flavia Titia; CIL II 5323, Aurelia Flavia; CIL II 344, Flavius Avitus; CIL II 395 , G. Flavius Baeticus; AE 1905, 24, C. Flavius Baeticus; EE 9, 116, M. Flavius Celsus; CIL II 266. [-] Flavius M.f. Quadratus, ILER 4964, M. Flavius Rufus; CIL II5172, Q. Flavius Seranus; CIL II 505, T. Flavius Sexticius; AE 1979, 334, G. Flavius L.f. Toncius; AE 1985, 531, Flavius Turius Felix; AE 1967, 138, Flavius [-]; ILER 121, Flavius? Albinus; AE 1983, 480, Flavii? Paratus?, Paratus? y Tongius/a?; AE 1986, 278 Adn., Flavius? Severus. Es difícil precisar la procedencia extraprovincial o no de algunos individuos de condición libre: AE 1975, 472, Tib, Flavius Laetus; ILER 6130, Flavius Satrianus; CIL II 6254.14, Flaviuus Cornelianus?. 
romana o latina, en base a la política romanizadora flavia ${ }^{99}$, aunque también hallamos algún caso de promoción excepcionalmente temprana ${ }^{100} \mathrm{e}$ incluso un pequeño núcleo de individuos que usa el gentilicio inapropiadamente ${ }^{101}$. Un segundo grupo cuantitativamente significativo entre los Flavii lo constituirían los individuos de ascendencia servil, que en buena medida serían también de procedencia provincial ${ }^{102}$, aunque la presencia de onomástica griega siempre introduce un factor de incertidumbre sobre su origen ${ }^{103}$, que incluso en algún caso nos consta que podría ser greco-oriental ${ }^{104}$. Finalmente, sólo de forma muy puntual se inserta en el grupo gentilicio algún sujeto de posible procedencia itálica en testimonios epigráficos preflavios ${ }^{105}$.

En cuanto a los aspectos socioeconómicos, en general apenas contamos con datos sobre sus actividades profesionales y posibles fuentes de riqueza, si bien es cierto que algunos de los Flavii lusitanos llegaron a alcanzar una notable promoción pública, como evidencia la figura de la emeritense Flavia Rufina, flaminica provincial, y un nivel económico acomodado, caso del grupo de dueños de esclavos y patronos de libertos ubicados en Emerita, la civitas Igaeditanorum y Balsa, situación solvente compartida incluso a veces por alguno de estos libertos. Ahora bien, el grueso de los Flavii lusitanos son individuos de tipo modesto, alejados de las élites municipales y provinciales, del ejercicio de cargos públicos, y

99 De forma más clara sería el caso en Emerita de CIL II 505, T. Flavius Sexticius, hijo de lanuarius Venusti f. emeritensis, de finales del s. I o comienzos del s. I d.C.; quizá también los de DE 183 = CIL II 32, Flavia L.f. Rutina, flaminica provincial y su familia a finales del s. d.C.; FRA taf.72A, T. Flavius Amethystus, su esposa Flavia Firmana y su hijo T. Flavius Beryllus, de época Antonina, posiblemente libertos acomodados de una familia que obtuvo la ciudadanía bajo los Flavios.

$100 \mathrm{AE} 1979,334$, G. Flavius L.f. Gal. Toncius, y CIL II 266, [-] Flavius M.f. Gal. Quadratus, ambos en la zona de Olisipo.

101 CIL II 908, Flavia Caeli Flavi; CIRS 127, Flavia Flavi; ILER 3210, Flavia; RE 49, Flavius?; RH 481, Flavius.

102 Seguramente asi era en los casos de ILER 4964, M. Flavius Primus en Emerita; CIL 11 5168, C. Flavius Relatus en Balsa; AE 1996, 859, Flavius Ariston, AE 1996, 858, Flavius Zosimus, ILER 5061, Flavii? Carus, Gemellus y Lucrio en la civitas Igaeditanorum.

103 Asi, es dificil precisar el origen foráneo o provincial de un grupo de libertos de Emerita: AE 1967, 209, Flavius Summachus y su esposa Flavia Ambasia; HEP 3, 96, Flavia Elpis; FRA Taf. 72A, T. Flavius Amethystus, su esposa Flavia Firmana y su hijo T. Flavius Beryllus; ILER 4386, T. Flavius Eutyches y su esposa Flavia lustina; ILER 3455, Flavius Neapolitanus, su esposa Flavia? Sabina, sus hijos Salvina, Recepta, Menander, y su nieto lustinus.

104 CIL II 179, Flavia Tyche en Olisipo.

105 Podrían ser de ascedencia itálica los casos de VL 24, C. Flavius A.f. en Conquista de la Sierra (Cáceres); AE 1967, 190, C. Flavius C.t. Pap. Sabinus, natural de Emerita pero quizá descendiente de itálicos. 
cuya implicación en la epigrafía honorífica y monumental es nula, aunque muestren generalmente una notable romanización onomástica.

En relación a la distribución territorial del nomen Flavius en la provincia, resulta claro que el grueso de los testimonios se aglutina en el convento Emeritense (51\%), pero hay que tener presente que más de los dos tercios de los documentos de este convento se localizan en Emerita Augusta, concentración que se explica posiblemente por la alta fuerza de atracción que la colonia ejercía como capital conventual y provincial. También es muy notable cuantitativamente la presencia de Flavii en el convento Scallabitano $(34 \%)$, pero sin una concentración tan marcada en un lugar determinado como en el Emeritense. La incidencia menor del mismo es sin duda en la zona más al sur de la provincia, en el convento Pacense (15\%). Además, la ubicación de los Flavii suele estar estrechamente ligada al ámbito urbano y así les hallamos vinculados a ciudades de distinta importancia y su área inmediata de influencia. Un $48 \%$ de los Flavii se ubican en núcleos de promoción preflavia (Emerita, Norba, Olisipo, Salacia), grupo que resulta ser el mayoritario precisamente gracias a la alta acumulación de testimonios en Emerita. Frente a éstos, un $37 \%$ de los portadores del nombre gentilicio se sitúan en núcleos de los que o bien se conoce su estatus de municipio flavio, o al menos se les vincula con los efectos de la política urbanizadora y romanizadora de los emperadores Flavios en Lusitania: este grupo sería mínimo en el convento Emeritense (23\% frente al $71 \%$ ubicado en núcleos de promoción preflavia), y de mayor peso en el concento Pacense (40\% frente al 30\% ubicados en núcleos de promoción preflavia) y sobre todo en el Scallabitano (57\% frente a un $22 \%$ ubicados en núcleos de promoción preflavia). Finalmente, un $15 \%$ de los Flavii lusitanos se localizan en núcleos poblacionales secundarios, privados de promoción jurídica pero con una economía dinámica y buena situación con respecto a la red viaria.

En cuanto a su expansión cronológica, conviene tener presente que no disponemos de una datación realmente precisa para casi la mitad de los documentos recogidos. A pesar de ello, el análisis de este aspecto indica que el nomen Flavius hace su aparición en Lusitania en época preflavia en el convento Emeritense y Scallabitano (Emerita, el área de Turgalium, y Olisipo). Sin embargo se trata de testimonios excepcionales, ya que el gentilicio se extiende por la provincia básicamente desde finales del s. I y en el s. "I d.C. Por el contrario, son muy raros los testimonios de Flavii en etapas más tardías (ss. III-IV d.C.), situación que contrasta con las fuentes epigráficas de la Bética y la Tarraconense, donde el nomen Flavius muestra una clara tendencia a permanecer en la Antigüedad Tardía (ss. IVvı d.C.), en alguna ocasión asociado a miembros de las altas jerarquías de 
la administración imperial, circunstancia también constatada en Lusitania a través del testimonio del comes Tib. Flavius Laetus, pero sobre todo relacionado con fuentes de carácter paleocristiano, especialmente significativas en la Bética, y aunque también se hallan en la Tarraconense, en esta provincia son más característicos entre los Flavii tardoantiguos documentos de fuerte sabor indígena del norte y noroeste peninsular.

Parece, por tanto, que la incorporación masiva de los flavii lusitanos al hábito epigráfico se produce desde finales del s. I y durante el s. II d.C., lo que apuntaría a los efectos de la política romanizadora flavia como la causa principal de la expansión del nomen en Lusitania ${ }^{106}$. Atendiendo a la distribución del mismo en el territorio, serían los conventos Emeritense y Scallabitano en los que la incidencia de esta política sería mayor, siendo menores los efectos en el Pacense. Además, su distribución en los núcleos urbanos provinciales liga de forma importante la dispersión del gentilicio Flavius en Lusitania a los núcleos de promoción flavia (municipios flavios o comunidades de derecho latino), muy especialmente en el convento Scallabitano, pero en realidad esta situación resultaría ampliamente mayoritaria en toda la provincia de no ser por la importante acumulación de Flavii en Emerita Augusta. Ciertamente, la alta capacidad para atraer población de importantes colonias y municipios de temprana promoción puede explicar en gran medida la presencia de Flavii en los mismos, en concreto en Emerita, Norba, Olisipo y Salacia, individuos procedentes presumiblemente de otros núcleos beneficiados jurídicamente gracias a la política romanizadora flavia ${ }^{107}$, atraídos por las mejores y

106 Sobre la importancia que las motivaciones de la promoción del estatus jurídico personal tienen en la expansión del hábito epigráfico en las provincias del Imperio Romano Occidental, cfr. E. A. MEYER, "Explaining the Epigraphic Habit in the Roman Empire: the Evidence of Epitaphs", JRS, LXXX, 1990, 83-87.

107 La comparación entre la distribución territorial del gentilicio Flavius y de sus cognomina derivados en el convento Emeritense resulta poco concluyente, ya que los derivados aparecen en los mismos lugares que el gentilicio, es decir, en la propia Emerita, en Caesarobriga y en Ciudad Rodrigo, y a mayores los hallamos en Caurium y su entorno, núcleo de derecho latino flavio (P. LE Roux, “Droit Latin...», 253), pero en esta zona resulta que el antropónimo Flavus está muy extendido, por lo que es dificil determinar si estos cognomina derivados proceden en realidad del nomen Flavius o del cognomen Flavus. La misma comparación en el convento Scallabitano revela igualmente que Flavius y sus cognomina derivados coexisten en Olisipo, Conimbriga, la civitas Igaeditanorum, y en puntos de la franja norte del convento, junto al Duero (S. Joao da Fresta, Romariz), aunque a mayores los cognomina derivados se localizan también en Midôes (Bobadella), núcleo que debió ser un municipio flavio ( $P$. LE Roux, "Droit Latin...", 252). En el convento Pacense los cognomina derivados se localizan sin embargo en los núcleos de Myrtilis y Ebora, donde no se constata el gentilicio Flavius. De todos modos, también el cognomen Flavus se constata en muchos de los puntos donde hallamos los cognomina derivados en los conventos Scallabitano y Pacense, cfr. nota 71. 
más variadas posibilidades económicas y sociales de estas urbes. Sin embargo, tampoco podemos desestimar otras posibilidades, como una promoción jurídica personal en época flavia, por motivos variados, de distintos individuos en estas antiguas colonias y municipios, como parece ser el caso en Emerita de T. Flavius Sexticius, que dedica un monumento funerario a su padre lanuarius Venusti (f.) emeritensis, o de la familia de la flaminica Flavia L.f. Rufina emeritensis ${ }^{108}$, ambos a finales de s. I o principios del s. II d.C., así como la expansión del gentilicio a través de los esclavos manumitidos, o la constatación de la presencia del nomen Flavius ya en época preflavia, aunque sea muy puntualmente, en Emerita y Olisipo, lo que introduce un factor ajeno a la política de los emperadores Flavios en la expansión del gentilicio, al menos en estas dos ciudades.

Tabla de datos epigráficos*: los Flavii en la Lusitania

\begin{tabular}{|c|c|c|c|c|c|c|c|}
\hline PR. NOMEN & COGNOMEN & STATUS & DATO SOCIAL & DIVINIDAD & LUGAR DE HALLAZGO & $\mathrm{FECHA}$ & BIBLIOGRAFIA \\
\hline FLAVIA & & & & & TALAVERA DE LA REINA (TOLEDO) & $\|$ & CIL $\| 908$ \\
\hline FLAVIA & & & & & HINOJOSA DE DUERO (SALAMANCA) & $\|$ & CIRS 127 \\
\hline FLAVIA & & & & & SERPA (BAJO ALENTEJO, PORTUGAL) & $\|$ & HER 3210 \\
\hline FLAVIA & & & & DII MANES & CONDEIXA-ANOVA (PORTUGAL) & $\|$ & CIL $\| 366$ \\
\hline FLAVIA & AMBASIA & L? & & & CAMPOLUGAR (CACERES) & MIIICIII & AE 1967,209 \\
\hline FLAVIA & ELPIS & L? & & & MERIDA (BADAJOZ) & $\|-\| \|$ & HEP 3.96 \\
\hline FLAVIA & FIRMANA & & & & MERIDA (BADAJOZ) & $C\|\cdot M\|$ & FRA TAF.72A \\
\hline FLAVIA & FLAVINA & & & DII MANES & MERIDA (BADAJOZ) & $\|$ & ClL $\| 521$ \\
\hline FLAVIA & USTINA & L? & & & MERIDA (BADAJDZ) & MIICCIII & ILER 4380 \\
\hline FLAVIA & LUPERCILLA & & & & $\begin{array}{l}\text { ROMAO DO SADO } \\
\text { (ALÇOCER DO SAL: PORTUGAL) }\end{array}$ & !ll & DE 191 \\
\hline FLAVIA & MAXSIMA-SIC & & & & MACEIRA (LEIRIA, PORTUGAL) & FlMil & EEg, 28 \\
\hline FLAVIA & PATRICIA & & & ADECINA & STA.LUCIA (ALCUESCAR. CACERES) & $\mathrm{C} \|$ & NQ 11 \\
\hline FLAVIA & RUFINA & & & & VILLAR DEL PEDROSO (CACERES) & it & RH 658 \\
\hline FLAVIA & RUFNA & 1 & $\begin{array}{l}\text { FLAMINICA } \\
\text { PROVINCIAE }\end{array}$ & $\begin{array}{l}\text { IUPPITER } \\
\text { OPTIM. MAX. }\end{array}$ & ALCOCER DO SAL (PORTUGAL) & $\mathrm{Fl}$ & CIL $\mid 132$ \\
\hline FLAVIA & SEVERA & & & & ELVAS (PORTUGAL) & $\mathrm{Fi} \cdot \| \mathrm{II}$ & DE 598 \\
\hline $\begin{array}{l}\text { FLAVIA } \\
\text { TITIA }\end{array}$ & & & & $\begin{array}{l}\text { VENUS } \\
\text { VICTRIX AUG. }\end{array}$ & SANTIAGO DO CACYEM (PORTUGAL) & $\|1\|$ & CIL $\| 23$ \\
\hline
\end{tabular}


El nomen Flavius en Lusitania: su inserción en las estructuras onomásticas y ...

Tabla de datos epigráficos*: los Flavii en la Lusitania (continuación)

\begin{tabular}{|c|c|c|c|c|c|c|c|}
\hline PR. NOMEN & COGNOMEN & STATUS & DATO SOCIAL & DIVINIDAD & LUGAR DE HALLAZGO & FECHA & BIELLOGRAFIA \\
\hline FLAVIA & TYCHE & & CERNOPHORA & $\begin{array}{l}\text { MATER DELMM } \\
\text { MAGNA }\end{array}$ & LISBOA (PORTUGAL) & $\mathrm{C} \|$ & CILIII 179 \\
\hline FLAVIA? & FLAVINA & & & & CIUDAD RODRIGO (SALAMANCA) & $\| \mathrm{CH}$ & CIRS 33 \\
\hline FLAVIA? & RECEPTA & L? & & & MERIDA (BADAJOZ) & H-Cliil & ILER 3455 \\
\hline FLAVIA? & SABINA & L? & & & MERIDA (BADAJOZ) & $\|-C !\|$ & ILER 3455 \\
\hline FLAVIA? & SALVINA & L? & & & MEFIDA (BADAJOZ) & $\|-C\|$ & ILER 3455 \\
\hline FLAVIUS? & & & & & CONDEIXA-ANOVA (PORTUGAL) & $\|$ & RE 49 \\
\hline FLAVIUS & & & & & TALAVERA LA VIEJA ICACERES) & $\|$ & RH 481 \\
\hline A. FLAVIUS & & & & & CONQUISTA DE LA SIERRA (CACERES) & C.MI & V24 \\
\hline C. FLAVIUS & & & & & MERIDA (BADAJOZ) & $!$ & AE 1967.190 \\
\hline C. FLAVIUS & & & & HERCULES & $\begin{array}{l}\text { CONQUISTA DE } \\
\text { LA SIERRA (CACERES) }\end{array}$ & $C|\cdot M|$ & VL 24 \\
\hline L. FLAVIUS & & & & & ALCOCER DO SAL (PORTUGAL) & $\mathrm{Fl}$ & $\mathrm{CLL} \| 32$ \\
\hline L. FLAVIUS & & & & & ASSAFORA (LISBOA, PORTUGAL) & 1 & AE 1979,334 \\
\hline M. FLAVIUS & & & & & TERRUGEM (SINTRA. LISBOA, PORTUGAL) & । & CLL $\| 266$ \\
\hline T. FLAVUUS & AMETHYSTUS & L? & & DII MANES & MERIDA (BADA.JOZ) & CII-M\| & FRA TAF. 72A \\
\hline FLAVIUS & ARISTON & $L$ & & MARS & IDANHA A VELHA (PORTUGAL) & H:till & AE 1996,859 \\
\hline FLAVIUS & AVITUS & & & & COS (ALCOBAÇA, LEIRIA, PORTUGAL) & $\|\cdot\|$ & CIL I| 344 \\
\hline C. FLAVIUS & BAETICUS & D & & & MERIDA (BADAJOZ) & $\|\cdot C\|$ & AE 1905,24 \\
\hline G. FLAVIUS & BAETICUS & & & & TENTUGAL (COMMBRA, PORTUGAL) & $\mathrm{Fl} \cdot \mathrm{CH}$ & CIL I| 395 \\
\hline T. FLAVIUS & BERYLLUS & & & DII MANES & MERIDA (BADAJOZ) & CHIMH & FRA TAF.72A \\
\hline M. FLAVIUS & CELSUS & & & $\begin{array}{l}\text { IUPPITER } \\
\text { OPTIM. MAX. }\end{array}$ & CACERES & $\|$ Clil & EE9; 116 \\
\hline FLAVIUS & CORNELIANUS & $D$ & & & TORRE D'ARES (TAVIRA, PORTUGAL) & H. H & CIL $\|$ 6254.14 \\
\hline T. FLAVIUS & EUTYCHES & L? & & DIM MANES & MERIDA (BADAJOZ) & $M\|\cdot C\|$ & ILER 4386 \\
\hline FLAVIUS & FLAVUS & & & DIIMANES & CONDEIXA-A.NOVA (PORTUGALI) & $\|$ & CIL $\| 366$ \\
\hline TIB. FLAVIUS & LAETUS & SN & $\begin{array}{l}\text { VIR } \\
\text { CLARISSIMUS, } \\
\text { COMES }\end{array}$ & & MERIDA (BADAJOZ) & N & AE 1975,472 \\
\hline FLAVIUS & NEAPOLITANUS & L? & & & MERIDA (BADAJOZ) & $\|-C\|$ & ILER 3455 \\
\hline M. FLAVIUS & PRIMUS & $\mathrm{l}$ & & & MERIDA (BADAJOZ) & FH-MUH & ILER 4964 \\
\hline 1. FLAVIUS & QUADRATUS & I & $\begin{array}{l}\text { AQUULIFER } \\
\text { LEGIONIS }\end{array}$ & & TERRIUGEM (SINTRA, LISBOA, PORTUGAL) & $\hat{C}|M|$ & CIL $\| 266$ \\
\hline C. FLAVIUS & RELATUS & L? & & DII MANES & TORRE D'ARES (TAVIRA, PORTUGAL) & MI.FH & CIL II 5168 \\
\hline M. FLAVIUS & RUFUS & $P$ & & & MERIDA (BADAJOZ) & Fl-Mil & ILER 4964 \\
\hline C. FLAVIUS & SABINUS & & & & MERIDA (BADANOZ) & I & AE 1967,190 \\
\hline
\end{tabular}

(continuación) 


\section{Tabla de datos epigráficos*: los Flavii en la Lusitania (continuación)}

\begin{tabular}{|c|c|c|c|c|c|c|c|c|}
\hline PR. & NOMEN & COGNOMEN & STATUS & DATO SOCIAL & DIVINIDAD & LUGAR DE HALLAZGO & FECHA & BIBLIOGRAFIA \\
\hline & FLAVIUS & SATRIANUS & & & & MERIDA (BADA.JOZ) & $\|-\| \|$ & UEER 6130 \\
\hline Q. & FLAVIUS & SERANUS & & & & TORRE D'ARES (TAVIRA, PORTUGAL) & $\|$ & CLL II 5172 \\
\hline \multirow[t]{2}{*}{ T. } & $\begin{array}{l}\text { FLAVIUS } \\
\text { SEXTICIUS }\end{array}$ & & & & DII MANES & MERIDA (BADAJOZ) & $\mathrm{FI} \cdot \mathrm{CHI}$ & CLL $\| 505$ \\
\hline & FLAVIUS & SUMMACHUS & L? & & & CAMPOLUGAR (CACERES) & MIIICLIII & AE 1967, 209 \\
\hline \multirow[t]{5}{*}{ G. } & FLAVIUS & TONCIUS & & & & ASSAFORA (LISBOA, PORTUGAL) & 1 & AE 1979,334 \\
\hline & FLAVIUS & zosimus & L? & & & IDANHA A VELHA (PORTUGAL) & $H-\| 11$ & AE 1996,858 \\
\hline & FLAVIUS & {$[\cdots]$} & & & MARS & IDANHA A VELHA (PORTUGAL) & il:ill & AE 1967, 138 \\
\hline & $\begin{array}{l}\text { FLAVUUS } \\
\text { TURIUS }\end{array}$ & FELIX & & & VORTIAECH? & PENAMACOR (PORTUGAL) & $\|-\| H$ & AE 1985,531 \\
\hline & FLAVUUS? & ALBINUS & & & $\begin{array}{l}\text { IUPPITER } \\
\text { OPTIM. MAX. }\end{array}$ & MEIMAO (PENAMACOR, PORTUGAL) & $\|-\| \|$ & ILER 121 \\
\hline & FLAVIUS? & CARUS & $\mathrm{L}$ & & & IDANHA (PORTUGAL) & $|\cdot||| \mid$ & ILEF 5061 \\
\hline & FLAVIUS? & GEMELLUS & $L$ & & & IDANHA (PORTUGAL) & $|\cdot| \cdot||$ & ILER 5061 \\
\hline & FLAVIUS? & IUSTINUS & L? & & & MERIDA (BADAJOZ) & $\|$.CIII & ILER 3455 \\
\hline & FLAVIUS? & LUCRIO & $L$ & & & IDANHA (PORTUGAL) & $|-\|| \mid$ & ILER 5061 \\
\hline & FLAVIUS? & MENANDER & L? & & & MERIDA (BADAJOZ) & $\|$.Cllt & ILER 3455 \\
\hline & FLAVIUS? & PARATUS? & & & & LAMEGO (PORTUGAL) & $F\|-\| \|$ & AE 1983,480 \\
\hline & FLAVUUS? & PARATUS? & & & DII MANES & LAMEGO (PORTUGAL) & $F\|-\| \|$ & AE 1983,480 \\
\hline & FLAVIUS? & SEVERUS & & & DEA SANCTA & $\begin{array}{l}\text { VLLA VERDE DE FICALHO (SERPA, } \\
\text { PORTUGAL) }\end{array}$ & |ll & $\begin{array}{l}\text { AE 1986, } \\
278 A D N\end{array}$ \\
\hline & FLAVUUSAA? & & $p$ & & & IDANHA (PORTUGAL) & $|\cdot|||$ & ILER 5061 \\
\hline & FLAVUUS $-A$ & ?TONGIUS/A? & & & & LAMEGO (PORTUGAL) & FII-III & AE 1983,480 \\
\hline & $\begin{array}{l}\text { AURELLA } \\
\text { FLAVIA }\end{array}$ & & & & OIIMANES & TALAVERA DE LA REINA (TOLEDO) & $\|\cdot C\|$ & CLI $\| 5323$ \\
\hline & $\begin{array}{l}\text { ELIGIUS } \\
\text { FLAVIUS }\end{array}$ & & & & & CIUDAD RODRIGO (SALAMANCA) & H.CH & CIRS 33 \\
\hline
\end{tabular}

* ABREVIATURAS DE LA BIBLIOGRAFIA REFERIDA A FUENTES EPIGRÁFICAS

AE: Année Épigraphique, Paris, 1900-1996

$\mathrm{CIL}$ : Corpus inscriptionum Latinarum, vol. II y suppl.

CIRS:S. Chespo ORTIZ de Zafate/A. Alonso AVILA, Corpus de inscripciones romanas de la provincia de Salamanca. Fuentes epigráficas para la Historia social de Hispania romana, Valladolid, 1999

DE: J. D'ENCARAACAO, Inscriçoes romanas do Conventus Pacensis, Coimbra, 1984.

EE: Ephemeris Epigraphica, vol. VIII y IX

FRA: G. Gamer, Former romischer Altare aut der Hispanischen Halbinsel, Mainz, 1989

HEP: Hispania Epigraphica, Departamento de Historia Antigua. Universidad Complutense. Madrid.

ILER: J. VIVES, Inscripciones Latinas de la España Romana, Barcelona. 1972.

NQ: J. Salas Martin/J. Rosco Madruga, "Epigrafía latina votiva de Santa Lucía del Trampal. I. (Alcuéscar. Cáceres)", Norba, 13, 1993, 63-103.

RE: J. AlaRCAO/R. ETIEnNe, Fouilles de Conimbriga. II, París, 1976

RH: R. HuRtado SAN Antonio, Corpus provincial de inscripciones latinas de Cáceres, Cáceres, 1977.

VL: H. Gimeno/A. Stylow, "Juan Pérez Holguín y la epigrafía trujillana", Veleia, 10, 1993, 117-178 